\title{
Haematological response to iron supplementation is reduced in children with asymptomatic Helicobacter pylori infection
}

\author{
Dilip Mahalanabis ${ }^{1}$, M. Aminul Islam ${ }^{2}$, Saijuddin Shaikh ${ }^{1}$, Monilal Chakrabarty ${ }^{3}$, Anura V. Kurpad ${ }^{4}$, \\ Swagata Mukherjee ${ }^{5}$, Bandana Sen ${ }^{1}$, M. Abu Khaled ${ }^{2}$ and Sten H. Vermund ${ }^{2}$ \\ ${ }^{1}$ Society for Applied Studies, 108 Maniktala Main Road, Flat-3/21, Kolkata - 700 054, India \\ ${ }^{2}$ University of Alabama at Birmingham, Birmingham, Alabama, USA \\ ${ }^{3}$ Kothari Medical Research Centre, Kolkata, India \\ ${ }^{4}$ St. Johns Medical College, Bangalore, India \\ ${ }^{5}$ Infectious Diseases Hospital, Kolkata, India
}

(Received 11 November 2004 - Revised 20 May 2005 - Accepted 20 July 2005)

\begin{abstract}
We evaluated the adverse effect of asymptomatic Helicobacter pylori infection in children on the response to Fe supplementation. One hundred and sixtynine children aged 1-10 years from the urban poor community underwent a $\left[{ }^{13} \mathrm{C}\right]$ urea breath test for $\mathrm{H}$. pylori and haematological tests at admission and after 8 weeks. Both $H$. pylori-positive and -negative children were randomly assigned to receive ferrous fumarate syrup ( $20 \mathrm{mg}$ elemental Fe twice daily) or placebo for 8 weeks and a single dose of vitamin A $(33,000 \mu \mathrm{g})$. Admission findings were compared between $H$. pylori-positive and -negative children. Response to $\mathrm{Fe}$ was compared between Fe-supplemented $H$. pylori-positive and -negative children. Seventy-nine per cent of the children were aged $1-5$ years and half of them were boys. In eighty-five H. pylori-positive and eighty-four H. pylori-negative children, the differences in mean $\mathrm{Hb}$ (112 (SD

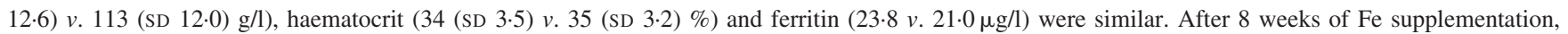
mean $\mathrm{Hb}$ was $5.3 \mathrm{~g} / \mathrm{l}$ more $(95 \% \mathrm{CI} 1.59,9.0)$ and haematocrit was $1.4 \%$ more $(95 \%$ CI $0.2,2.6)$ in $H$. pylori-negative $(n$ 44) compared with $H$. pyloripositive $(n 42)$ children. Mean ferritin was similar at admission and improved in both H. pylori-positive and -negative children. Asymptomatic H. pylori infection was not associated with higher rates of anaemia or Fe deficiency in children, but had a significant adverse effect on response to Fe therapy. However, this result is based on exploratory analysis and needs confirmation.
\end{abstract}

Helicobacter pylori: Anaemia: Children: Iron supplementation: Iron status

The prevalence of Helicobacter pylori infection is very high in children of developing countries and in many of them it occurs in early infancy (Mahalanabis et al. 1996; Bardhan, 1997; Sarker et al. 1997). The vast majority of these children do not present with any overt symptoms and signs attributable to this infection, which is known to cause gastritis and altered gastric acid secretion (El-Omar et al. 1997; Gutierrez et al. 1997; Sarker et al. 2004). Infection with H. pylori has been incriminated as a cause of anaemia refractory to treatment with Fe supplements (Peach et al. 1998; Annibale et al. 1999; Choe et al. 1999, 2000, 2003a; Konno et al. 2000; Ashorn et al. 2001) and several case reports have shown that its eradication improves the anaemia (Choe et al. 1999, 2000; Konno et al. 2000; Ashorn et al. 2001; Sugiyama et al. 2002; Sarker et al. 2004). Lactoferrin is known to provide $\mathrm{Fe}$ for $H$. pylori in gastric mucosa. In an elegant study Choe et al. (2003a) showed that adolescents with H. pyloriassociated gastritis coexisting with anaemia had very high levels of lactoferrin in the gastric mucosa, and eradication of $H$. pylori in them was associated with a significant fall of lactoferrin level in gastric mucosa along with a rise in $\mathrm{Hb}$ concentration. The authors suggested that the phenomenon of sequestration of lactoferrin in the gastric mucosa in subjects with $H$. pylori gastritis and
Fe-deficiency anaemia might lead to a better understanding of the mechanism of anaemia in H. pylori gastritis. Recently Sarker et al. (2004) showed that gastric acid secretion is significantly reduced in $H$. pylori-infected anaemic young children and its eradication restores gastric acid secretion. Absorption of Fe from two $\mathrm{Fe}$ salts, namely ferrous sulfate (water-soluble) and ferrous fumarate (water-insoluble but soluble in weak acids), in asymptomatic children aged 2-5-years infected with $H$. pylori was, however, not significantly different from that in children free of $H$. pylori infection (Sarker et al. 2004).

Fe-deficiency anaemia remains a major nutritional problem in developing countries, particularly in children and women of childbearing age, and is an important cause of morbidity. In India, the National Family Health Survey II conducted in 1998/99 documented that about $74 \%$ children aged between 6 and 35 months were anaemic (Kapil, 2003).

We hypothesized that asymptomatic $H$. pylori infection in children would be associated with Fe-deficiency anaemia and that its presence would also adversely affect the response to $\mathrm{Fe}$ supplementation of children in developing countries. To address these primary research questions we conducted exploratory and subgroup analysis within a randomized, double-blind, 
placebo-controlled trial of daily Fe supplementation along with an initial single large dose of vitamin A in children and evaluated the role of $H$. pylori infection on response to Fe supplementation by measuring $\mathrm{Hb}$, haematocrit and ferritin values. Analysis comparing the response to Fe supplements in children with asymptomatic $H$. pylori infection and children without such infection (i.e. a subgroup in the trial) was pre-specified in the study design. We shall report separately the results of the randomized controlled trial of Fe supplementation with ferrous fumarate in underprivileged urban children in India, which was a secondary objective of the study.

\section{Methods}

Study population and sample selection

Children aged 1 to 10 years, of either sex, were included in the study. Additional inclusion criteria were no antibiotics during the past month, no sign/symptoms of infection, no gastrointestinal complaints such as diarrhoea, staying within a reasonable distance of the clinic $(<3 \mathrm{~km})$ and parents willing to give consent. Children attending the well baby clinic at the Infectious Diseases and Beliaghata General Hospital, Kolkata, India were approached for participation in the study. This is a large general hospital run by the government where treatment is free or subsidized and serves the urban poor. The medical officer (S.M.) of the clinic invited parents of the children in order of their registration and the first two eligible ones were recruited for the day. Written consent was obtained from the parents. The recruitment took place between June 1999 and October 2000. Baseline history and clinical examination results on the children enrolled were recorded on a pre-tested data collection form. These included age, sex, weight, height, mid-arm circumference and selected socio-economic indicators. The tests done at admission to the study included determinations of $\mathrm{Hb}$, haematocrit, ferritin, serum $\mathrm{Fe}$ and total Fe-binding capacity, and a $\left[{ }^{13} \mathrm{C}\right]$ urea breath test to detect $H$. pylori infection. The blood tests were repeated after 8 weeks of intervention. The study was approved by the Ethical Review Committees of the Society for Applied Studies, Kolkata, India and the University of Alabama at Birmingham, USA.

\section{Randomization and treatments}

A master randomization chart was prepared using permuted blocks of random numbers of variable block length (2, 4 and 6) by a person not directly involved in the conduct of the study. The sequence in which block lengths would appear was ascertained using a random number table. This randomization was incorporated into the serially numbered bottles of Fe syrup or placebo syrup, so that the serial numbers of a set of bottles corresponded to the patient's serial numbers. The randomization code was kept sealed centrally and was provided to the investigators only after they submitted the data sets on completion of the study. The children after recruitment received the supplement from the numbered bottles corresponding to their serial number, prior to any knowledge about whether the child was $H$. pyloripositive or -negative, because breath samples for the $\left[{ }^{13} \mathrm{C}\right]$ urea breath test were analysed in batch mode and the results were available only after completing the treatment protocol. Children were randomly assigned to receive Fe syrup daily or a placebo (identical in colour, consistency and taste) for 8 weeks. In addition, all children received at the start of Fe therapy a single large dose $(33,000 \mu \mathrm{g})$ of vitamin A. Subclinical vitamin A deficiency is common in this population and a single dose of vitamin A was given to all children at the start to improve response to Fe supplementation. Children were provided with four bottles of Fe syrup or placebo along with a plastic measure and their mothers were instructed to administer $5 \mathrm{ml}$ syrup twice daily. Each $\mathrm{ml}$ of syrup contained $4 \mathrm{mg}$ elemental $\mathrm{Fe}$ as ferrous fumarate. Therefore, all children in the intervention group would receive a daily dose of $40 \mathrm{mg}$ elemental $\mathrm{Fe}$ (four times the RDA (Food and Nutition Board, National Research Council 1989) for 1-10-year-olds). Children received the first dose of the syrup at the clinic under the supervision of the health worker before being sent home with an appointment to return to the clinic after 4 weeks. At 4 weeks, parents were asked about syrup intake and side-effects if any, and a second set of four bottles was given for the second 4 weeks with an appointment to return at 8 weeks for final evaluation.

Random allocation to two groups resulted in the following four groups: (i) H. pylori-positive children treated daily with Fe syrup; (ii) H. pylori-positive children treated daily with placebo syrup; (iii) H. pylori-negative children treated daily with Fe syrup; and (iv) H. pylori-negative children treated daily with placebo syrup.

\section{Follow-up procedures}

Children were asked to return to the clinic after 4 weeks or earlier if they felt the need. If they missed the appointment at 4 weeks, a home visit was made to ascertain the reason and to encourage them to come. An appointment for a second visit at 8 weeks was given and if they failed, a home visit was made to encourage them to return.

\section{Sample size}

For comparison between $H$. pylori-positive and -negative children and to detect a difference of $5 \mathrm{~g} / \mathrm{l}$ in $\mathrm{Hb}$ between the two groups at admission, seventy-five children would be needed in each group based on an expected mean Hb level of $110 \mathrm{~g} / \mathrm{l}$ with SD of $11 \mathrm{~g} / \mathrm{l}$ (at $80 \%$ power and $95 \%$ confidence). For evaluating the difference in response to Fe supplementation between $H$. pylori-positive and H. pylori-negative children with an expected difference in mean $\mathrm{Hb}$ of $8 \mathrm{~g} / \mathrm{l}$, we would need forty $H$. pylori-positive and forty $H$. pylori-negative children in the Fe-supplemented group. Using a conservative estimate that $50 \%$ would be positive for $\mathrm{H}$. pylori, we would need to recruit a total of 160 children for the subgroup analysis. We added $5 \%$ more to this figure to compensate for loss to follow-up.

\section{Statistical considerations and data analysis}

We planned to make comparisons at two levels. At enrolment, the haematological indices were compared between $H$. pylori-positive and -negative children. For evaluation of the role of $H$. pylori infection on the response to $\mathrm{Fe}$ supplementation, we compared the haematological indices in the Fe-supplemented $H$. pylori-positive children with those in the Fe-supplemented $H$. pylori-negative children (i.e. groups (i) and (iii)) at admission and after 8 weeks of supplementation. This subgroup would constitute about half of the children enrolled in the trial. This analysis plan was pre-specified and is reflected in the sample size calculation given above. 
EpiInfo version 6.0 (Centers for Disease Control and Prevention, Atlanta, GA, USA and WHO, Geneva, Switzerland) was used for entering and editing data. To evaluate the association of $H$. pylori infection with Fe deficiency and/or anaemia, all children recruited into the trial were divided into two groups according to $H$. pylori infection status. Their baseline features were summarized and compared. Their haematological indices at admission were compared by one-way ANOVA, a non-parametric test or the $\chi^{2}$ test. Where relevant, use of appropriate regression models (multiple linear regression and logistic regression) was planned to adjust for covariates.

To evaluate the effect of $H$. pylori infection on the response to Fe we used multiple linear regression models. As a first step all children in the trial were included in the model and the interaction between Fe treatment and $H$. pylori infection was evaluated along with other explanatory and/or confounding factors. Separate models were fitted with $\mathrm{Hb}$, haematocrit or ferritin values at 8 weeks after supplementation. Treatment effect was modelled with the interaction term between treatment and $H$. pylori status along with other baseline features such as sex and age. We then directly compared the subgroups of children with and without $H$. pylori infection treated with Fe supplement to evaluate the role of $H$. pylori infection on the treatment outcome. Regression models were used on this subgroup for evaluating treatment effect on $\mathrm{Hb}$, haematocrit and ferritin with $H$. pylori status, sex and age as covariates. These models provided estimates for the role of $H$. pylori infection on the response to Fe supplementation. For regression models we used Stata version 7.0 software (Stata Corporation, College Station, TX, USA).

\section{Laboratory analyses}

$\left[{ }^{13} \mathrm{C}\right]$ Urea breath test. The $\left[{ }^{13} \mathrm{C}\right]$ urea breath test has high specificity and sensitivity and is widely accepted as a non-invasive technique for diagnosing current $H$. pylori infection (Logan et al. 1991; Vandenplas et al. 1991). $\left[{ }^{13} \mathrm{C}\right]$ Urea is degraded rapidly in the presence of $H$. pylori urease to ${ }^{13} \mathrm{CO}_{2}$ and $\mathrm{NH}_{3}$, and the former is excreted in the breath. A baseline breath sample was collected. The child then drank about $100 \mathrm{ml}$ milk, followed by a test dose of $\left[{ }^{13} \mathrm{C}\right]$ urea $\left(99 \%\left[{ }^{13} \mathrm{C}\right]\right.$ urea; Sigma, St. Louis, MO, USA) at a dose of $30 \mathrm{mg}$ for children less than 24 months old and $40 \mathrm{mg}$ for children older than 24 months, dissolved in $50 \mathrm{ml}$ sterile water. After $30 \mathrm{~min}$ the second breath sample was collected. Older children who were able to cooperate were asked to blow air through a tube into a plastic bag with an attached needle. Vacutainer tubes were filled using the attached needle. For younger children, not able to cooperate, a facemask with a one-way outlet valve was used to collect breath directly into a Vacutainer tube. Samples were collected in duplicate. Breath samples were analysed for ${ }^{13} \mathrm{C}$ of respiratory $\mathrm{CO}_{2}$ by GC-isotope ratio MS at St. John's Medical College, Bangalore, India. Breath samples with an excess over baseline enrichment of ${ }^{13} \mathrm{C}>\Delta 5.0 \%$ were regarded positive for $H$. pylori infection. The $\left[{ }^{13} \mathrm{C}\right]$ urea breath test has been shown to be $100 \%$ sensitive and $92 \%$ specific and is considered a reference standard for the diagnosis of $H$. pylori infection in children (Rowland et al. 1997).

Haematological tests. Venous blood samples $(2.5 \mathrm{ml})$ were drawn; $0.5 \mathrm{ml}$ was taken into an EDTA-treated tube and analysed for $\mathrm{Hb}$ using the cyanmethaemoglobin (colorimetric) method (Randox ${ }^{\circledR}$ kit; Randox Laboratories, San Diego, CA, USA) and the remaining $2 \mathrm{ml}$ was taken into a plain tube and treated to obtain serum. Serum Fe and total Fe-binding capacity were determined using a colorimetric method (Randox ${ }^{\circledR}$ kit; Randox Laboratories). For ferritin, a solid-phase immunoradiometric assay based on monoclonal and polyclonal anti-ferritin antibodies was used (Coat-A-Count Ferritin IRMA kit; Diagnostics Products Corporation, Los Angeles, CA, USA). The radioactivity is measured using a gamma counter and the concentration of ferritin is obtained by comparing the counts per minute with those obtained for the set of calibrators provided. The calibrators contain ferritin in terms of the WHO Second International Reference Preparation of Ferritin for Immunoassay, number 80/578 (2nd IS 80/578).

\section{Results}

Two hundred and forty-one children were assessed for eligibility and 176 children were recruited in the study (Fig. 1). Seven withdrew before the $\left[{ }^{13} \mathrm{C}\right]$ urea breath test for the diagnosis of $H$. pylori infection could be done. Of the 169 children, eighty-five were positive and eighty-four were negative for $H$. pylori infection by the $\left[{ }^{13} \mathrm{C}\right]$ urea breath test (Table 1). The two groups were similar in terms of age, sex and anthropometric indicators such as weightfor-age, weight-for-height and height-for-age SD scores compared with the National Center for Health Statistics (Dibley et al. 1987) reference data, and mid-arm circumference. The proportion of illiterate mothers was marginally higher in the $H$. pylori-positive children.

Haematological indices for $H$. pylori-positive and -negative children at admission are compared in Table 2. Mean Hb, haematocrit, serum $\mathrm{Fe}$, total and unsaturated Fe-binding capacity, the proportions with low $(<12 \mu \mathrm{g} / \mathrm{l})$ serum ferritin and the geometric mean serum ferritin concentrations were not significantly different between the two groups. About $40 \%$ of the children were anaemic as defined by $\mathrm{Hb}<110 \mathrm{~g} / \mathrm{l}$.

Eighty-three children were randomized to the placebo group, of whom forty-three were positive and forty negative for $\mathrm{H}$. pylori. Haematological indices at admission and after 8 weeks of supplementation with placebo were similar between the H. pylori-positive and -negative groups, and between admission and 8 -week values in each group (data not shown).

In three separate regression models on all children in the trial we evaluated the effect of the interaction between $H$. pylori infection and $\mathrm{Fe}$ treatment on $\mathrm{Hb}$ concentration, haematocrit and ferritin after 8 weeks of supplementation (Table 3). A trend for a negative interaction was noted for $\mathrm{Hb}$ concentration $(-4.5$; $95 \%$ CI $2.15,-11.15)$ and haematocrit $(-1.2 ; 95 \%$ CI 0.73 , $-3 \cdot 13$ ). A positive interaction was seen for ferritin concentration (ratio of geometric means $=1.67 ; 95 \%$ CI 1.02, 2.75).

Among the Fe-supplemented subgroup, forty-two children were positive and forty-four were negative for $H$. pylori. Haematological indices at admission and after 8 weeks of supplementation are shown in Table 4. Two in the H. pylori-negative group defaulted at the final evaluation at 8 weeks. Eight children (five in the H. pylori-positive and three in the H. pylori-negative group) did not receive $\mathrm{Fe}$ syrup for the second 4 weeks but returned for final evaluation at 8 weeks. These eight children were included in the analysis. Upon daily $\mathrm{Fe}$ supplementation the children with $H$. pylori infection had no significant increase in mean blood $\mathrm{Hb}$ concentration, whereas the $H$. pylori-negative children had a significant rise, with a mean increase in $\mathrm{Hb}$ of $5.3 \mathrm{~g} / \mathrm{l}$ (95\% CI 1.59, 9.00; $P \leq 0.001)$ compared with baseline values. Similarly, the $H$. pylori-negative children had a significant rise in haematocrit values after Fe supplementation compared with 


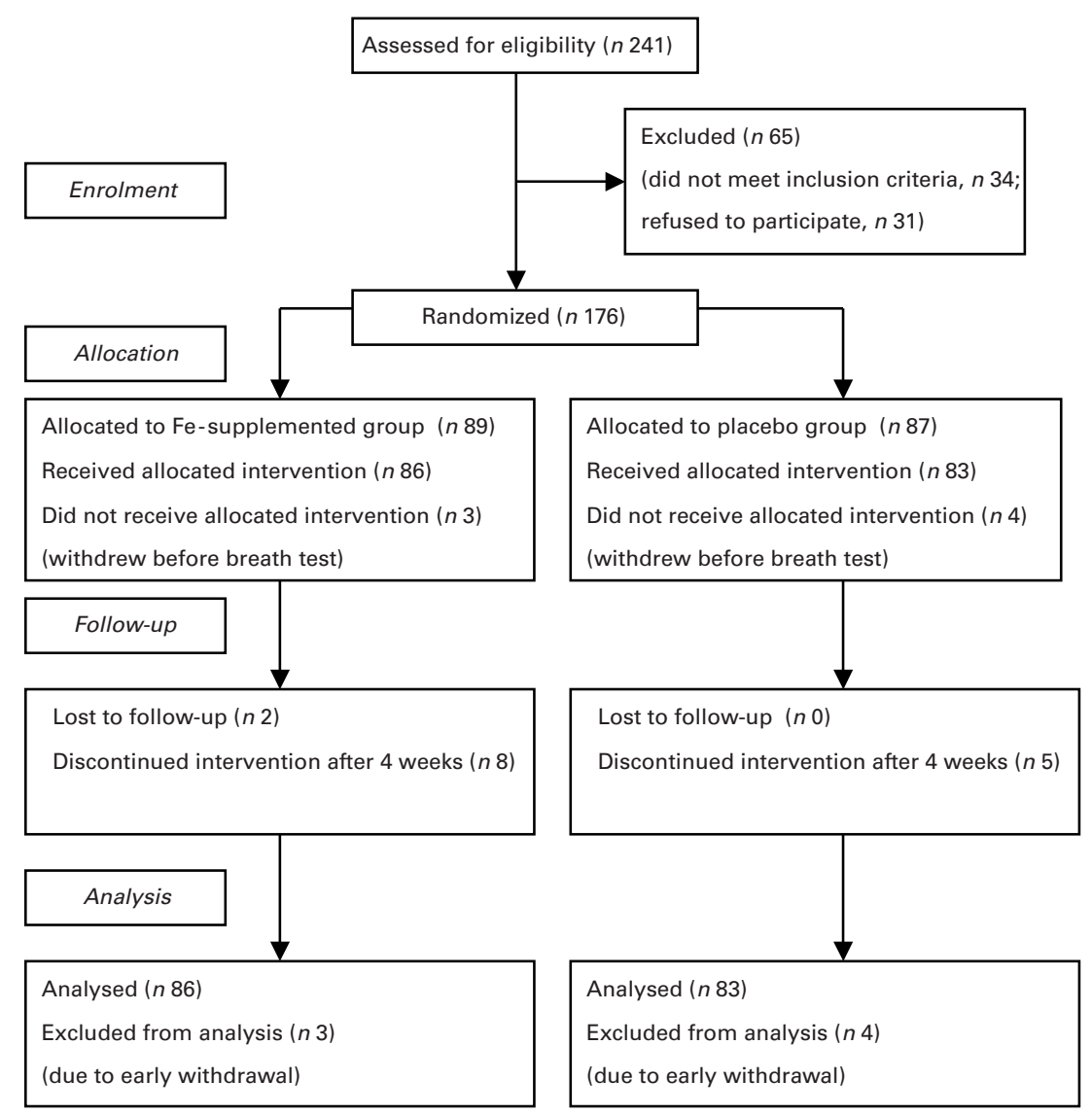

Fig. 1. Flow diagram showing subject recruitment.

admission values of $1.34 \%$ (95\% CI 0.07, 2.62), but there was no significant increase in the $H$. pylori-positive children. After 8 weeks of $\mathrm{Fe}$ supplementation the proportion of children with $\mathrm{Hb}<110 \mathrm{~g} / \mathrm{l}$ was nearly double in the $H$. pylori-positive children compared with the $H$. pylori-negative ones (relative risk $=1.9$; $95 \%$ CI 1.04, 3.48; $P=0.029)$. Furthermore, after 8 weeks of $\mathrm{Fe}$ supplementation, $\mathrm{Hb}$ and haematocrit values were higher in the H. pylori-negative children than in -positive ones (Table 4). There was no significant difference in serum ferritin values between the two groups after Fe supplementation. However, Fe supplementation resulted in a significant fall in the proportion of children with serum ferritin $<12 \mu \mathrm{g} / \mathrm{l}$ in both groups compared with admission values. Moreover, the proportion with low ferritin levels (i.e. $<12 \mu \mathrm{g} / \mathrm{l}$ ) was substantially reduced as a whole after Fe supplementation (i.e. in H. pylori-positive and -negative children taken together) compared with the two placebo groups combined (relative risk $=15 ; 95 \%$ CI 2, 653; $P=0.002$; data not shown). Using regression models on all children in the trial we could also show that the geometric mean ferritin level after 8 weeks of supplementation was $54 \%$ higher in the Fe-supplemented group than in the placebo group (ratio of geometric means $=1.54 ; 95 \%$ CI $1.20,1.97 ; P=0.001)$. There was a trend for total $(P=0.076)$ and unsaturated $(P=0.087)$ Fe-binding capacity to be higher in $H$. pylori-positive children after Fe supplementation compared with $H$. pylori-negative ones. No significant difference was noted in serum $\mathrm{Fe}$ values either at admission or after Fe supplementation. We used separate regression models with $\mathrm{Hb}$ and haematocrit as dependent variables and $H$. pylori infection along with admission value of $\mathrm{Hb}$ or haematocrit as independent variable to estimate the adverse effect of $H$. pylori infection in the subgroup of children who received Fe supplements (data not shown). The results were closely similar to unadjusted analyses (Table 4). The presence of $H$. pylori infection was associated with a reduction of $5.27 \mathrm{~g} / \mathrm{l}$ in $\mathrm{Hb}(95 \%$ CI 1.31 ,

Table 1. Baseline characteristics of Helicobacter pylori-positive and -negative children as determined by the $\left[{ }^{13} \mathrm{C}\right]$ urea breath test

(Values are means and standard deviations or $n(\%)$ unless stated otherwise)

\begin{tabular}{|c|c|c|c|c|}
\hline \multirow[b]{2}{*}{ Characteristic } & \multicolumn{2}{|c|}{$\begin{array}{c}\text { H. pylori-positive } \\
(n 85)\end{array}$} & \multicolumn{2}{|c|}{$\begin{array}{c}\text { H. pylori-negative } \\
(n \text { 84) }\end{array}$} \\
\hline & Mean & SD & Mean & SD \\
\hline Age (months) ${ }^{*}$ & \multicolumn{2}{|c|}{$42 \cdot 0(29,60)$} & \multicolumn{2}{|c|}{$37.5(25.5,57.5)$} \\
\hline \multicolumn{5}{|l|}{ Age group (years) } \\
\hline $1-2$ & \multicolumn{2}{|c|}{$13(15 \cdot 3)$} & \multicolumn{2}{|c|}{$19(22 \cdot 6)$} \\
\hline$>2-3$ & \multicolumn{2}{|c|}{$24(28 \cdot 2)$} & \multicolumn{2}{|c|}{$20(23.8)$} \\
\hline$>3-5$ & \multicolumn{2}{|c|}{$27(31.8)$} & \multicolumn{2}{|c|}{$31(36.9)$} \\
\hline$>5$ & \multicolumn{2}{|c|}{$21(24 \cdot 7)$} & \multicolumn{2}{|c|}{$14(16 \cdot 7)$} \\
\hline Boys & \multicolumn{2}{|c|}{$43(50 \cdot 6)$} & \multicolumn{2}{|c|}{$42(50.0)$} \\
\hline Weight-for-age $Z$ score $†$ & -1.82 & 1.00 & -1.93 & 0.92 \\
\hline Weight-for-height $Z$ score $†$ & -1.40 & 0.95 & -1.43 & 0.76 \\
\hline Height-for-age $Z$ score $†$ & $-1 \cdot 20$ & $1 \cdot 21$ & -1.38 & $1 \cdot 30$ \\
\hline Mid-arm circumference $(\mathrm{cm})$ & $14 \cdot 3$ & 1.48 & 13.9 & $1 \cdot 19$ \\
\hline Illiterate mother & \multicolumn{2}{|c|}{$35(41 \cdot 2)$} & \multicolumn{2}{|c|}{$23(27 \cdot 4)$} \\
\hline
\end{tabular}

*Median (quartiles).

† Compared with the National Center for Health Statistics reference data. 
Table 2. Admission laboratory findings of Helicobacter pylori-positive and -negative children (Values are means and standard deviations or $n(\%)$ unless stated otherwise)

\begin{tabular}{|c|c|c|c|c|c|}
\hline & \multicolumn{2}{|c|}{$\begin{array}{l}\text { H. pylori-positive } \\
(n \text { 85) }\end{array}$} & \multicolumn{2}{|c|}{$\begin{array}{l}\text { H. pylori-negative } \\
(n \text { 84) }\end{array}$} & \multirow[b]{2}{*}{$95 \% \mathrm{Cl}$} \\
\hline & Mean & SD & Mean & SD & \\
\hline $\mathrm{Hb}(\mathrm{g} / \mathrm{l})$ & 112 & $12 \cdot 6$ & 113 & $12 \cdot 0$ & $-4 \cdot 74,2 \cdot 74$ \\
\hline Haematocrit (\%) & 34.0 & 3.5 & 34.5 & 3.2 & $-1.52,0.52$ \\
\hline Ferritin $\left(\mu \mathrm{g} / \mathrm{l}^{*}\right.$ & \multicolumn{2}{|c|}{$23 \cdot 8$} & \multicolumn{2}{|c|}{21.0} & $0.87,1.47 \dagger$ \\
\hline Ferritin level $<12 \mu \mathrm{g} / \mathrm{l}$ & \multicolumn{2}{|c|}{$16 / 81(19.8)$} & \multicolumn{2}{|c|}{$18 / 76(23.7)$} & $0.46,1.51 \dagger$ \\
\hline Serum Fe $(\mu \mathrm{g} / \mathrm{dl})$ & $67 \cdot 7$ & 33.4 & $69 \cdot 1$ & 33.0 & $-11.48,8.68$ \\
\hline Unsaturated Fe-binding capacity (units) & $256 \cdot 8$ & 79.8 & 248.5 & 84.6 & $-16 \cdot 67,33 \cdot 27$ \\
\hline Total Fe-binding capacity (units) & $325 \cdot 1$ & 83.4 & $312 \cdot 7$ & 84.9 & $-13 \cdot 16,37.96$ \\
\hline \multicolumn{6}{|l|}{$\mathrm{Hb}(\mathrm{g} / \mathrm{l})$} \\
\hline$\leq 100$ & \multicolumn{2}{|c|}{$9(10 \cdot 6)$} & \multicolumn{2}{|c|}{$8(9.5)$} & \\
\hline$>100$ to $<110$ & \multicolumn{2}{|c|}{$25(29.4)$} & \multicolumn{2}{|c|}{$23(27 \cdot 4)$} & \\
\hline$\geq 110$ & \multicolumn{2}{|c|}{$51(60.0)$} & \multicolumn{2}{|c|}{$53(63 \cdot 1)$} & \\
\hline
\end{tabular}

* Geometric mean.

† Ratio mode.

None of the differences between the two groups were significant (ANOVA or $\chi^{2}$ test). Analysis adjusted for sex and age showed no significant difference between the two groups (regression models).

Table 3. Effect of interaction between Helicobacter pylori infection and treatment with Fe supplements on $\mathrm{Hb}$, haematocrit and serum ferritin after 8 weeks of treatment for all children in the trial

(Values are mean effect with $95 \% \mathrm{Cl}$ in parentheses)

\begin{tabular}{|c|c|c|c|}
\hline \multirow[b]{2}{*}{ Variable* $^{*}$} & \multicolumn{3}{|c|}{ Effect on } \\
\hline & $\mathrm{Hb}(\mathrm{g} / \mathrm{l})$ & Haematocrit (\%) & Ferritin $(\mu \mathrm{g} / \mathrm{l}) \dagger$ \\
\hline Interaction (between treatment and H. pylori) & $-4 \cdot 50(2 \cdot 15,-11 \cdot 15)$ & $-1.20(0.73,-3.13)$ & $1.67(1.02,2.75)$ \\
\hline$P$ value & 0.18 & 0.22 & 0.04 \\
\hline
\end{tabular}

* Separate multiple linear regression models were fitted for $\mathrm{Hb}$, haematocrit and ferritin values after 8 weeks of supplementation (dependent variables) on all children in the trial. Other variables in the models are treatment with $\mathrm{Fe}, \mathrm{H}$. pylori status, sex, age and admission values of $\mathrm{Hb}$ or haematocrit or ferritin (log-transformed).

$\dagger$ Ferritin was modelled after log transformation and therefore the effect and confidence interval are in ratio mode.

$\ddagger H$. pylori: present $=1$, absent $=0$; treatment with $\mathrm{Fe}$ : yes $=1$, no $=0$.

Table 4. Laboratory findings at enrolment and after 8 weeks of supplementation with iron and vitamin A (Values are means and standard deviations or $n(\%)$ unless stated otherwise)

\begin{tabular}{|c|c|c|c|c|c|c|c|c|}
\hline & \multicolumn{4}{|c|}{ Helicobacter pylori-positive (n 42) } & \multicolumn{4}{|c|}{ Helicobacter pylori-negative ( $n$ 42) } \\
\hline & \multicolumn{2}{|c|}{ Admission } & \multicolumn{2}{|c|}{8 weeks } & \multicolumn{2}{|c|}{ Admission } & \multicolumn{2}{|c|}{8 weeks } \\
\hline & Mean & SD & Mean & SD & Mean & SD & Mean & SD \\
\hline $\mathrm{Hb}(\mathrm{g} / \mathrm{l})$ & $113 \cdot 1$ & $11 \cdot 1$ & $113 \cdot 8 \ddagger$ & $9 \cdot 2$ & $112 \cdot 4$ & $9 \cdot 5$ & $119 \cdot 1 \ddagger$ & $7 \cdot 8$ \\
\hline Haematocrit (\%) & $34 \cdot 1$ & 3.3 & $34.5 \S$ & $2 \cdot 9$ & 34.4 & $2 \cdot 9$ & $35.9 \S$ & $2 \cdot 6$ \\
\hline Ferritin $(\mu \mathrm{g} / \mathrm{l})^{\star}$ & \multicolumn{2}{|c|}{$26(15,38)$} & \multicolumn{2}{|c|}{$35(28,52)$} & \multicolumn{2}{|c|}{$21(15,30)$} & \multicolumn{2}{|c|}{$28(24,56)$} \\
\hline Ferritin $<12 \mu \mathrm{g} / \mathrm{l} \dagger$ & \multicolumn{2}{|c|}{$9 / 41(22 \cdot 0)$} & \multicolumn{2}{|c|}{$1 / 27(3 \cdot 7)$} & \multicolumn{2}{|c|}{$7 / 38(18.4)$} & \multicolumn{2}{|c|}{$0 / 29(0.0)$} \\
\hline Serum Fe $(\mu \mathrm{g} / \mathrm{dl})$ & $62 \cdot 0$ & $26 \cdot 9$ & $82 \cdot 1$ & $36 \cdot 3$ & $71 \cdot 8$ & $36 \cdot 2$ & 71.5 & $27 \cdot 5$ \\
\hline Unsaturated Fe-binding capacity (units) & 258.5 & $69 \cdot 4$ & $241 \cdot 7 \|$ & $62 \cdot 5$ & $242 \cdot 0$ & $80 \cdot 8$ & $209 \cdot 4 \|$ & $55 \cdot 5$ \\
\hline Total Fe-binding capacity (units) & $324 \cdot 8$ & $65 \cdot 1$ & 321.61 & $68 \cdot 7$ & $308 \cdot 2$ & $84 \cdot 8$ & $287 \cdot 81$ & $46 \cdot 8$ \\
\hline $\mathrm{Hb}<110 \mathrm{~g} / \mathrm{l}$ & \multicolumn{2}{|c|}{$13(30 \cdot 9)$} & \multicolumn{2}{|c|}{$20(47 \cdot 6)^{\star *}$} & \multicolumn{2}{|c|}{$17(40 \cdot 5)$} & \multicolumn{2}{|c|}{$11(26 \cdot 2)^{\star \star}$} \\
\hline
\end{tabular}

${ }^{*}$ Median (quartiles).

$\dagger P=0.043$ for $H$. pylori-positive (relative risk $=5.9 ; 95 \% \mathrm{Cl} 0.8,44.2$ ) and $P=0.016$ for $H$. pylori-negative children (Fisher's exact test, two-tailed) for comparison between admission and at 8 weeks.

$\ddagger$ Mean difference $=5.3(95 \% \mathrm{Cl} 1.59,9.00)$.

$\S$ Mean difference $=1.4(95 \% \mathrm{Cl} 0 \cdot 20,2 \cdot 60)$.

\| Mean difference $=32 \cdot 3(95 \% \mathrm{Cl} 6 \cdot 64,57 \cdot 96)$.

I Mean difference $=33.8(95 \% \mathrm{Cl} 8.28,59.32)$

${ }^{* \star} \mathrm{RR}=0.55,(95 \% \mathrm{Cl} 0.30$ to $1.00, P=0.041)$

Differences among the groups at admission were not significant at the $5 \%$ level. 
9.23) and a reduction of $1.34 \%$ in haematocrit (95\% CI 0.07 , 2.62). H. pylori infection was associated with a non-significant increase in serum ferritin of $20 \%(95 \% \mathrm{CI}-17,72)$.

Among children who received the placebo, forty-three were positive and forty were negative for $H$. pylori by the $\left[{ }^{13} \mathrm{C}\right]$ urea breath test. $\mathrm{Hb}$, haematocrit and serum ferritin values at 8 weeks were not significantly different from the admission values (data not shown). Likewise, serum $\mathrm{Fe}$, total and unsaturated Fe-binding capacities at 8 weeks were also similar to admission values in both groups.

\section{Discussion}

The present study confirmed that the prevalence of $H$. pylori infection is high in children from among the urban poor in India. One important finding was that both $\mathrm{Hb}$ concentrations and haematocrit values after 8 weeks of $\mathrm{Fe}$ supplementation were adversely affected by the presence of $H$. pylori infection. A major new finding was the absence of any adverse effect of H. pylori infection on improvement in serum ferritin concentration, which increased substantially in the presence of H. pylori infection. Improvement in ferritin concentration following $\mathrm{Fe}$ supplementation was not associated therefore with an improvement in $\mathrm{Hb}$ and haematocrit values in $H$. pylori-infected children. However, we conducted an exploratory subgroup analysis in a randomized controlled trial and the findings should therefore be interpreted with caution.

In the present study we could not demonstrate an association between asymptomatic $H$. pylori infection in children with anaemia or Fe status. However, we note that about $40 \%$ of the children had an initial $\mathrm{Hb}$ value less than $110 \mathrm{~g} / \mathrm{l}$ and was similar in the two groups. Nearly $80 \%$ of the children in this study were $1-5$ years old whereas the association between $H$. pylori infection and anaemia and/or Fe deficiency has been reported largely in older subjects. We speculate that a longer duration for $H$. pylori infection may be needed to show a difference.

We can only speculate on the reasons for this difference. Several studies (largely in older children, teenagers and adults) have shown that anaemia associated with $H$. pylori infection (Peach et al. 1998; Annibale et al. 1999; Konno et al. 2000; Ashorn et al. 2001; Choe et al. $2003 a, b$ ) is resistant to Fe supplementation unless H. pylori is eradicated (Choe et al. 1999, 2000; Sugiyama et al. 2002; Sarker et al. 2004). We speculate that lack of response to Fe supplementation in $H$. pylori-positive children could be due to (i) the presence of an inflammatory state associated with $H$. pylori infection (Yip \& Dallman, 1988; Crabtree, 1997; Hatz et al. 1997; Kirchner et al. 1997), or (ii) inadequate absorption in the presence of gastritis and/or reduced gastric acid secretion associated with H. pylori infection, or (iii) both. Improvement in ferritin status after Fe supplements in both $H$. pylori-positive and -negative children associated with a lack of improvement of anaemia in the H. pylori-positive children suggests that chronic infection with H. pylori may play a significant role. Unfortunately, we did not measure C-reactive protein or any other acute-phase reactant in our study children. Even though these children were asymptomatic, acute-phase response could have still occurred.

H. pylori contains an Fe-binding protein similar to ferritin and a system of Fe-repressive outer membrane proteins with ability to bind haem Fe (Jurado, 1997; Annibale et al. 2000). This raises the possibility of $H$. pylori competing with the host for Fe absorption, particularly for haem Fe.
We considered the role of infection and inflammation due to H. pylori in causing anaemia in the light of our findings and the reported improvement in anaemia after eradication of $H$. pylori by combined therapy with antibiotics in 2-5-year-old children in Bangladesh (Sarker et al. 2004). However, the degree of systemic inflammatory response associated with $H$. pylori infection has not been evaluated. Gastrointestinal blood loss associated with $H$. pylori infection as a cause of anaemia, as reported in one study (Kostaki et al. 2003), has not been confirmed (Sarker et al. 2004).

Using doubly labelled isotopes Sarker et al. (2004) directly measured $\mathrm{Fe}$ absorption from ferrous sulfate and ferrous fumarate in 2-5-year-old children in Bangladesh and showed that reduced gastric acid secretion associated with $H$. pylori infection did not significantly influence $\mathrm{Fe}$ absorption from these two salts. However, Fe absorption from ferrous fumarate was substantially lower in young children (2-5 years old) compared with ferrous sulfate (Sarker et al. 2004). Mean absorption of Fe from ferrous sulfate was more than triple that from ferrous fumarate. Eighty per cent of the children in the present study were $1-5$ years old and we can only speculate whether use of a more efficiently absorbed Fe salt such as ferrous sulfate would have been effective in improving anaemia in H. pylori-infected asymptomatic children. The dose used was four times the RDA for 1-10-year-old children. The younger children in the study may have received a relatively high therapeutic dose of $\mathrm{Fe}$ for 8 weeks. However, we expect the bioavailability of $\mathrm{Fe}$ from ferrous fumarate to be low.

Refractory anaemia associated with $H$. pylori infection has been reported in adolescent girls (Choe et al. 2000). In the present study we did not find any association of sex with anaemia or H. pylori infection.

The problem of anaemia and Fe deficiency in children in developing countries is overwhelming. The adverse effect of $H$. pylori infection on response to Fe supplementation makes it more difficult to design an adequate control strategy in populations with a high rate of asymptomatic $H$. pylori infection. A programme of treatment for $H$. pylori eradication in children from a developing country would be expensive, unrealistic and has doubtful ethical justification. In light of these findings it is worthwhile to explore if the use of different forms of $\mathrm{Fe}$ and/or Fe-absorption enhancers such as ascorbic acid would reduce this adverse effect in $H$. pylori-infected children.

\section{Acknowledgements}

This study was supported by the National Institutes of Health (NIH 5R03 DK 54 239-02), the Thrasher Research Fund and the Society for Applied Studies Trust. We thank Mr Jakir Hossain for assistance in data analysis and manuscript preparation and Mr Subodh Karmakar for editing and typing the manuscript.

\section{References}

Annibale B, Marignani M, Monarca B, Antonelli G, Marcheggiano A, Martino G, Mandelli F, Caprilli R \& Delle Fave G (1999) Reversal of iron deficiency anemia after Helicobacter pylori eradication in patients with asymptomatic gastritis. Ann Intern Med 131, 668-672.

Annibale B, Capurso G, Martino G, Grossi C \& Delle Fave G (2000) Iron deficiency anaemia and Helicobacter pylori infection. Int $J$ Antimicrob Agents 16, 515-519. 
Ashorn M, Ruuska T \& Makipernaa A (2001) Helicobacter pylori and iron deficiency anemia in children. Scand J Gastroenterol 36, 701-705.

Bardhan PK (1997) Epidemiological features of Helicobacter pylori infection in developing countries. Clin Infect Dis 25, 973-978.

Choe YH, Kim SK, Son BK, Lee DH, Hong YC \& Pai SH (1999) Randomized placebo-controlled trial of Helicobacter pylori eradication for iron-deficiency anemia in preadolescent children and adolescents. Helicobacter 4, 135-139.

Choe YH, Lee JE \& Kim SK (2000) Effect of Helicobacter pylori eradication on sideropenic refractory anemia in adolescent girls with Helicobacter pylori infection. Acta Paediatr 89, 154-157.

Choe YH, Oh YJ, Lee NG, Imoto I, Adachi Y, Toyoda N \& Gabazza EC (2003a) Lactoferrin sequestration and its contribution to iron-deficiency anemia in Helicobacter pylori-infected gastric mucosa. $J$ Gastroenterol Hepatol 18, 980-985.

Choe YH, Kim SK \& Hong YC (2003b) The relationship between Helicobacter pylori infection and iron deficiency: seroprevalence study in 937 pubescent children. Arch Dis Child 88, 178.

Crabtree JE (1997) Inflammatory mediators in gastroenterology. Overview. Eur J Gastroenterol Hepatol 9, 1023-1025.

Dibley MJ, Goldsby JB, Staehling NW \& Trowbridge FL (1987) Development of normalized curves for the international growth reference: historical and technical considerations. Am J Clin Nutr 46, 736-748.

El-Omar EM, Oien K, El-Nujumi A, Gillen D, Wirz A, Dahill S, Williams C, Ardill JE \& McColl KE (1997) Helicobacter pylori infection and chronic gastric acid hyposecretion. Gastroenterology 113, 15-24.

Food and Nutrition Board, National Research Council, Recommended dietary allowances 10th edn. Washington Dc: National Academy Press, 1989.

Gutierrez O, Melo M, Segura AM, Aangel A, Genta RM \& Graham DY (1997) Cure of Helicobacter pylori infection improves gastric acid secretion in patients with corpus gastritis. Scand J Gastroenterol 32, 664-668.

Hatz RA, Rieder G, Stolte M, Bayerdorffer E, Meimarakis G, Schildberg FW \& Enders G (1997) Pattern of adhesion molecule expression on vascular endothelium in Helicobacter pylori-associated antral gastritis. Gastroenterology 112, 1908-1919.

Jurado RL (1997) Iron, infections, and anemia of inflammation. Clin Infect Dis 25, 888-895.

Kapil U (2003) Prevention and control of iron deficiency anemia amongst young children. Indian Pediatr 40, 293-295.
Kirchner T, Steininger H \& Faller G (1997) Immunopathology of Helicobacter pylori gastritis. Digestion 58, 14-16.

Konno M, Muraoka S, Takahashi M \& Imai T (2000) Iron-deficiency anemia associated with Helicobacter pylori gastritis. J Pediatr Gastroenterol Nutr 31, 52-56.

Kostaki M, Fessatou S \& Karpathios T (2003) Refractory iron deficiency anaemia due to silent Helicobacter pylori gastritis in children. Eur J Paediatr 162, 177-179.

Logan RP, Polson RJ, Misiewicz JJ, Rao G, Karim NQ, Newell D, Johnson P, Wadsworth J, Walker MM, Baron JH (1991) Simplified single sample 13 carbon area breath test for Helicobacter pylori: comparison with histology, culture, and ELISA serology. Gut 32(12), 1461-1464.

Mahalanabis D, Rahman MM, Sarker SA, Bardhan PK, Hildelrand P, Beglinger C \& Gyr K (1996) Helicobacter pylori infection in infants and children in a poor community of Bangladesh: prevalence, socioeconomic and nutritional aspects. Int J Epidemiol 25, 894-898.

Peach HG, Bath NE \& Farish SJ (1998) Helicobacter pylori infection: an added stressor on iron status of women in the community. Med J Aust 169, 188-190.

Rowland M, Lambert I, Gormally S, Daly LE, Thomas JE, Hetherington C, Durnin M \& Drumm B (1997) Carbon 13-labeled urea breath test for the diagnosis of Helicobacter pylori infection in children. J Pediatr 131, 815-820.

Sarker SA, Mahalanabis D, Hildebrand P, Rahaman MM, Bardhan PK, Fuchs G, Beglinger C \& Gyr K (1997) Helicobacter pylori: prevalence, transmission, and serum pepsinogen II concentrations in children of a poor periurban community in Bangladesh. Clin Infect Dis 25, 990-995.

Sarker SA, Davidsson L, Mahmud H, Walczyk T, Hurrell RF, Gyr N \& Fuchs GJ (2004) Helicobacter pylori infection, iron, absorption, and gastric acid secretion in Bangladeshi children. Am J Clin Nutr 80, 149-153.

Sugiyama T, Tsuchida M, Yokota K, Shimodan M \& Asaka M (2002) Improvement of long-standing iron-deficiency anemia in adults after eradication of Helicobacter pylori infection. Intern Med 41, 491-494.

Vandenplas Y, Blecker U, Devreker T, Keppens E, Nijs J, Cadranel S, Pipeleers-Marichal M, Goossens A \& Lauwers S (1991) Contribution of ${ }^{13} \mathrm{C}$-urea breath test for the detection of Helicobacter pylori gastritis in children. Pediatrics 90, 608-610.

Yip R \& Dallman PR (1988) The role of inflammation and iron deficiency as causes of anemia. Am J Clin Nutr 48, 1295-1300. 